\title{
The high fibre diet in the treatment of diverticular disease of the colon
}

\author{
N. S. PAINTER \\ M.S., F.R.C.S., F.A.C.S. \\ The Manor House Hospital, London
}

\begin{abstract}
Summary
Diverticular disease of the colon causes symptoms even in the absence of inflammatory diverticulitis. These symptoms vary from vague dyspepsia to severe colic which may lead to resection of the sigmoid for 'diverticulitis'. This paper discusses the use of a high fibre diet, including miller's bran, in the treatment of uncomplicated diverticulosis. In the majority of cases this diet relieves symptoms and lessens the need for surgery in diverticular disease.
\end{abstract}

\section{Definitions}

A colonic diverticulum is an acquired herniation of the mucosa through the surrounding colonic muscle. The colon's circular muscle forms a complete tube while its longitudinal muscle is gathered into three taeniae, between which the colonic wall is thinner and here it is further weakened by the blood vessels which pierce it. These form tunnels along which diverticula commonly track so that the vessels bear to diverticula the same relationship as the spermatic cord does to an inguinal hernia (Drummond, 1917).

As diverticula enlarge, their muscle covering atrophies so that they cannot contract and expel faeces which harden into faecoliths that can be felt at operation.

Diverticula commonly occur in two rows on each side of the colon and less often on the antimesocolic border. This is because the lateral blood vessels are bigger and so most diverticula follow them and track into the fat of the appendices epiploicae (Slack, 1962). Hence diverticula are difficult to see at operation or at autopsy. This regular arrangement may be lost if recurrent inflammation distorts the colon's anatomy.

\section{The appearance of diverticulitis on the clinical scene}

Colonic diverticula were described very accurately over a hundred years ago by Gross (1845), Cruveilhier (1849), Rokitansky (1849), Haberschon (1857) and Klebs (1869). They believed that the diverticula were caused by constipation which caused some form of obstruction. In this deduction they were surprisingly accurate, as it was not until a century later when cineradiography became available that it was shown that diverticula were caused by segmentation leading to functional obstruction of the colon (Painter, 1962, 1964; Painter et al., 1965, Fig. 1).

Diverticula were regarded as harmless curiosities until Graser (1899) pointed out that they might lead to peritonitis and other lethal complications. In the next decade, diverticulitis appeared on the clinical scene with dramatic suddenness. Telling first saw the disease in 1899 and could find no one who was familiar with it but, by 1908, he could describe all the complications and, in 1917, he wrote his classic paper with Gruner. The disease, which was so new that by 1920 it had not found its way into the textbooks (Telling, 1920) had become, like appendicitis, in only 20 years 'a newly discovered bane of elders' (Bland-Sutton, 1920).

Since the turn of this century, diverticular disease has become a problem of increasing magnitude. In 1930 , diverticula were found in about $5 \%$ of colons over 40 years of age but now the disease affects $45 \%$ of Australian colons and $35 \%$ of British ones over the age of 60 . The incidence in France and the U.S.A. is similar. Thus within 70 years, the traditional lifespan of man, diverticular disease which was almost unknown in 1900 has become the commonest abnormality of the colon in the Western world (Painter and Burkitt, 1971).

\section{The pathogenesis of diverticulosis coli}

The pressures in the human colon, both in health and diverticulosis, and the effects of morphine, pethidine, prostigmine and probanthine upon the intracolonic pressures were studied by Painter (1962, 1964), Painter and Truelove (1964) and by Arfwiddson (1964). Cineradiography coupled with pressure recording shows that the colon produces localized high pressures by segmenting. Segmentation and pressure generation follow many stimuli such as eating, mechanical or emotional stress, as well as the drugs previously mentioned. The mechanism by which the segmented colon produces pressures is shown in Fig. 1. It acts not as an open tube but as a series of 'little bladders' whose outflow 

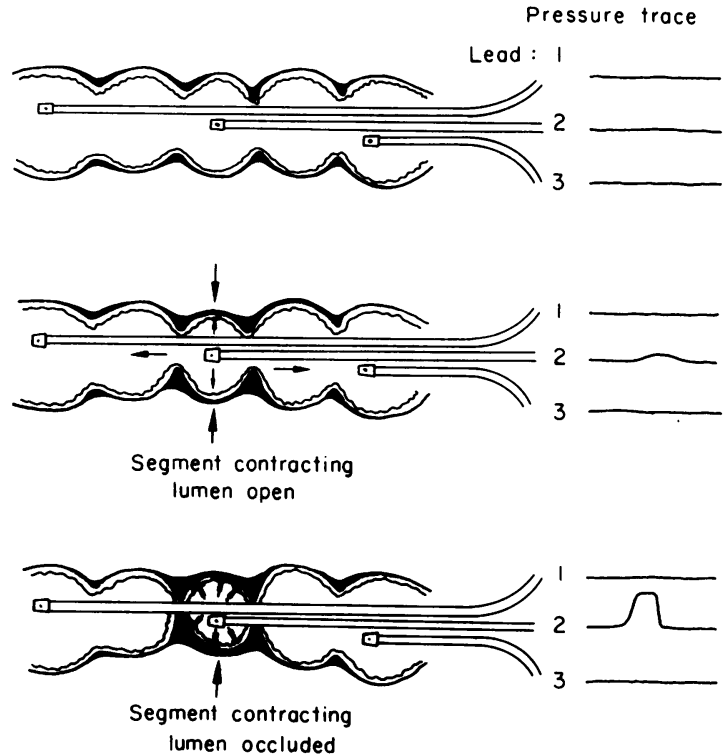

FIG. 1. Diagram to show mechanism of production of localized intracolonic pressure. This depicts open-ended recording tubes in longitudinal sections of colon, with the pressure tracings that would be derived from them. The top section shows a colon with haustral markings but with its lumen open. Changes of pressure brought about by small movements of its walls would be able to disperse rapidly along its open lumen and so no significant change in pressure would be recorded as no resistance to the movement of the colonic wall would be offered other than that due to the viscosity of its contents. The middle section shows a segment contracting when the lumen on each side of it is narrowed, but not occluded, by contraction rings. This segment's contents would be forced through the narrowed bowel on either side and the resistance to their flow thus encountered would result in a rise of pressure being recorded by Lead 2; the other two leads, being in open bowel, would be virtually unaffected. The bottom section shows a segment isolated from its fellows by contraction of the rings that bound it. Obviously, high pressure would be generated in this segment if it contracted; furthermore, this pressure would be localized to this segment and only be recorded by Lead 2 .

Reproduced by kind permission of the Editor of Gastroenterology.

is obstructed at both ends. High pressures in excess of $90 \mathrm{mmHg}$ may be generated and localized to a single segment which, in the same way as the obstructed urinary bladder, can generate pressure and become painful when its outflow is obstructed. These pressures cause 'trabeculation' of the muscle and eventually force the mucosa through the colonic wall (Painter, 1964; Painter et al., 1965).

Segmentation plays an important part in colonic physiology and is concerned in the transport and halting of the colon's contents (Fig. 2).

The aetiology of diverticular disease

The pathogenesis of diverticula was explained
A
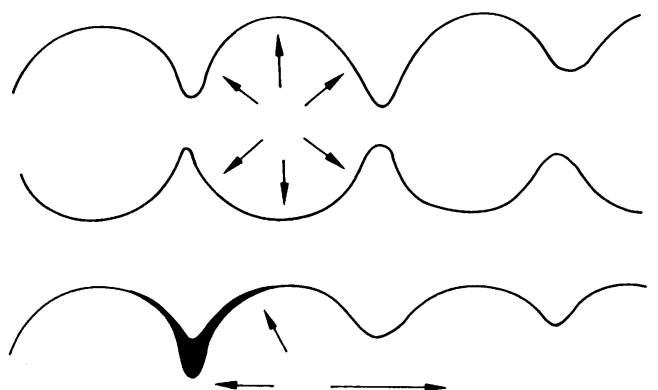

$B$

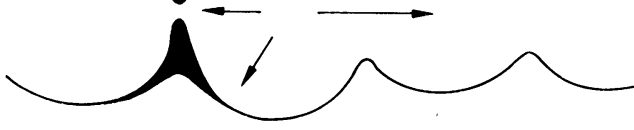

C
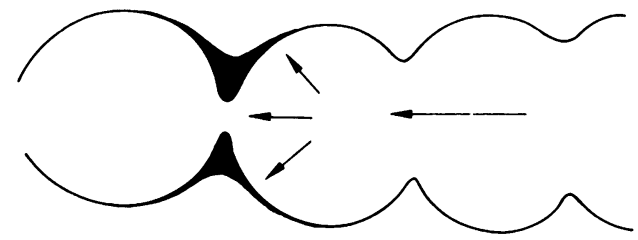

D

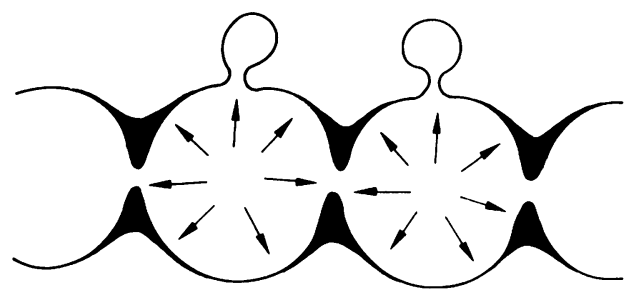

FIG. 2. The role of segmentation in colonic physiology. Diagram shows longitudinal section of colon which has segmented so as to localize high pressure to one segment (A). If the contraction ring bounding this segment relaxes, its contents will flow to the right to an area of lower pressures (B). Contraction rings can act as 'baffles' so as to halt the contents of the colon which are moving (C). In lowest section (D) the segmented colon is acting as a series of 'little bladders' each of which harbours a high pressure. This is how segmentation generates the pulsion force that causes the mucosa to herniate.

Reproduced by kind permission of the Editors of the Annals of the Royal College of Surgeons of England.

once segmentation was recognized, but the aetiology of the disease remained a mystery until its epidemiology and its history were studied. Diverticulosis has become common only in the economically developed countries of the West. By contrast, the disease is rare south of the Sahara and in rural Asia (Painter and Burkitt, 1971). For example, the most urbanized Africans are treated at the Baragwanath Hospital, Johannesburg but Keeley (1958) found no diverticula in 2367 autopsies performed between 1954 and 1956, while Soloman (1969, personal communication) saw none in 600 barium enema examinations. Davies 
found only two diverticula in 4000 autopsies in 15 years at Mulago Hospital, Kampala (Trowell, 1960). Admittedly, diverticula might be missed in small hospitals with limited facilities but it is inconceivable that acute diverticulitis, which frequently requires surgery and often causes death, would not have been recognized in African teaching hospitals with first-class staff and equipment and extensive autopsy experience. Questionnaires sent in 1971 to thirtyseven doctors serving rural hospitals revealed that they had seen only two cases of diverticular disease despite the fact that some of them had spent over 20 years in Africa (Painter and Burkitt, 1971).

The disease is still rare in rural Asians. Ten cases only were seen by Tinckler in one and a half million Chinese, Indian and Malay inhabitants of Singapore in 5 years but three cases were seen in 15,000 Europeans (Kyle et al., 1967). The disease is rare in Malaysia, Fiji, Iran, India, New Guinea and Korea and, for practical purposes, is seen only in expatriate Europeans or in local inhabitants who have adopted Western eating habits for a number of years (Kim, 1969; Painter and Burkitt, 1971).

The geographical distribution of diverticulosis shows that it is almost unknown in those peoples who have not changed their eating habits.

The British diet changed between the years 1870 and 1880 . Previously white flour had been made by sifting the bran from stoneground flour (McCance and Widdowson, 1956), but the introduction of roller milling further reduced the bran content of flour so that today white and brown bread contain only a trace of fibre. Concurrently increasing affluence, improvements in rail and sea transport and the advent of refrigeration made alternative foods available. Meat imports doubled and refined sugar and jam, which is $60 \%$ sugar, became part of the diet of even the poorest classes. The consumption of bread fell and this trend has continued to the present day except during the years of the two world wars.

Hence our intake of dietary fibre fell for two reasons: first because flour was refined still further by roller milling and, second because other foods, including refined sugar, became cheap and replaced the unrefined cereals that had previously been eaten (Barker, McKenzie and Yudkin, 1966).

Diverticulosis occurs in the second half of life and, if this change from a high fibre to a low fibre diet was responsible for its appearance, it would be expected to have become common in England 40 years after 1880 . In fact diverticulosis became common here by 1920 . Similarly, the American Negro was less prone to the disease before World War II than were his white compatriots (Kocour, 1937), but since he has been able to afford the same diet he is affected by the disease as often as is the White American (Cleave, Campbell and Painter, 1969).
Diverticulosis has appeared only recently in Tokyo where the diet has changed since the war but it is extremely common among Japanese in Hawaii (Stemmerman, 1970).

If fibre deficiency is responsible for diverticulosis, those communities who are now altering their eating habits and adopting a Western diet should develop the condition in about 30 years and its appearance should be heralded by an increased incidence of appendicitis. The latter is becoming common in affluent Africans and there should now follow the recognition of diverticulitis after a time interval similar to that which separated their appearance in Britain (Painter, 1969; Painter and Burkitt, 1971).

\section{Transit times, stool weights and diverticulosis}

The time between the ingestion of a foodstuff and the excretion of its unabsorbed residue may be measured by the method of Hinton, Lennard-Jones and Young (1969). Twenty-five radio-opaque plastic pellets are swallowed at a known time and the subsequent five stools passed are collected in plastic bags and X-rayed and weighed. The number of pellets in each stool is counted and, as the time of voiding each stool is known, the time taken for $20(80 \%)$ of the 25 pellets to traverse the alimentary tract can be calculated. This is called transit time.

This method can be used in villages where no expensive apparatus is available. It has shown that rural Ugandans eating a high fibre diet excrete over $450 \mathrm{~g}$ of soft stools daily without straining and have a transit time of about $35 \mathrm{hr}$. The average daily stool weight in America and Britain is less than $150 \mathrm{~g}$ and British naval ratings were shown to pass hard stools, usually with an effort, which weighed less than 110 $\mathrm{g}$ a day and which took 5 days to traverse the intestine.

This is not a racial phenomenon; African boarding school children eating a partly European diet passed about $185 \mathrm{~g}$ of stools a day with an average transit time of $45 \mathrm{hr}$. English vegetarians who eat more fibre than their compatriots have similar transit times and stool weights. Likewise, adding bran to the diet of Manor House Hospital patients yielded stool weights of $175 \mathrm{~g}$ a day and a transit time of about $41 \mathrm{hr}$ (Table 1). Hence dietary fibre profoundly affects the consistency of the stools and the speed at which they traverse the bowel (Burkitt, Walker and Painter, 1972). Consideration of Fig. 2 makes it obvious that less pressure is required to propel soft stools through the colon than is the case with very viscous ones.

In short, the swiftly passed stool resulting from a high fibre diet subjects the sigmoid to less strain and does not favour the development of diverticula. Hence the low residue diet which has been recommended for nearly 50 years should not be used to treat diverticulosis because it is the cause of the disease. 
TABLE 1. Transit times as shown by Hinton's method* $\dagger$

\begin{tabular}{|c|c|c|c|c|c|c|}
\hline Subjects & Country & Race & $\begin{array}{l}\text { Type of } \\
\text { diet }\end{array}$ & $\begin{array}{c}\text { Mean } \\
\text { transit } \\
\text { time } \\
\text { (hr) }\end{array}$ & $\begin{array}{c}\text { Mean } \\
\text { weight } \\
\text { of stools } \\
\text { passed (g) }\end{array}$ & Comments \\
\hline Naval ratings and wives & U.K. & White & Refined & $83 \cdot 4$ & 104 & Shore-based personnel \\
\hline $\begin{array}{l}\text { Teenage boarding } \\
\text { school pupils }\end{array}$ & U.K. & White & Refined & $76 \cdot 1$ & 110 & $\begin{array}{l}\text { Institutional diet together with cakes, } \\
\text { sweets, and so on from school shop }\end{array}$ \\
\hline Students & South Africa & White & Refined & $48 \cdot 0$ & 173 & $\begin{array}{l}\text { These ate more fruit than is usual in } \\
\text { the U.K. }\end{array}$ \\
\hline Nurses & South Africa & Indian & Mixed & $44 \cdot 0$ & 155 & $\begin{array}{l}\text { Less refined diet than that of western } \\
\text { world }\end{array}$ \\
\hline Urban schoolchildren & South Africa & African & Mixed & $45 \cdot 2$ & 165 & Partly Europeanized diet \\
\hline $\begin{array}{l}\text { Manor House Hospital } \\
\text { patients }\end{array}$ & U.K. & White & Mixed & $41 \cdot 0$ & 175 & $\begin{array}{l}\text { U.K. diet plus wholemeal bread and } \\
\text { added bran }\end{array}$ \\
\hline $\begin{array}{l}\text { Senior boarding school } \\
\text { pupils }\end{array}$ & Uganda & African & Mixed & $47 \cdot 0$ & 185 & $\begin{array}{l}\text { Traditional Ugandan diet plus refined } \\
\text { sugar, white bread, jam, butter }\end{array}$ \\
\hline Vegetarians & U.K. & White & Mixed & $42 \cdot 4$ & 225 & $\begin{array}{l}\text { Note similarity of values to those of } \\
\text { African groups }\end{array}$ \\
\hline Rural schoolchildren & South Africa & African & Unrefined & $33 \cdot 5$ & 275 & \\
\hline Rural villages & Uganda & African & Unrefined & $35 \cdot 7$ & 470 & $\begin{array}{l}\text { Villagers not yet supplementing their } \\
\text { diet with processed foods of } \\
\text { western type }\end{array}$ \\
\hline
\end{tabular}

* Modified from Burkitt et al., 1972.

$\dagger$ Note the inverse relationship between stool weight and transit time.

\section{Treatment of uncomplicated diverticular disease by the high fibre diet}

Strictly speaking, the high fibre diet should be called an unrefined diet. Ideally this should include plenty of fresh fruit, vegetables and above all wholemeal bread and flour. Our 19th century predecessors, who did not get diverticulosis, ate $20 \mathrm{oz}$ of this bread a day and consumed about half as much sugar as we do. Today most food is processed and it is difficult to obtain an unrefined diet cheaply. The old and those who have retired on a fixed income can often afford only the cheapest foods which have been refined to facilitate their storage and transport, and so may suffer from constipation and diverticulosis.

Fortunately cereal fibre can be added cheaply and safely to the diet by eating miller's bran. Its laxative effect is related to the amount ingested (Cowgill and Anderson, 1932) owing mainly to its ability to absorb water and so soften the faeces. Wheat bran contains up to $12 \%$ of fibre and this fibre has a greater laxative effect than that from fruit and vegetables. Dimock (1936) showed that bran was safe and effective in the treatment of constipation, mucous colitis and spastic colon. He used 'All-bran', but Cleave (1941; 1971, personal communication) used miller's bran in the Royal Navy and witnessed no complications during 30 years.

Painter, Almeida and Colebourne (1972) gave bran to patients with symptomatic diverticular disease without organic stenosis. The nature of the disease and its relationship to diet was explained to the patients who were told to increase their intake of bran until they did not have to strain to defaecate. They were advised to eat 'All-bran', 'Weetabix', porridge, $100 \%$ stoneground wholemeal (not brown) bread, fresh fruit and vegetables. They were asked to stop adding refined sugar, whether brown or white, to their drinks. After taking 2 teaspoons of bran three times a day for 2 weeks they were told to increase this amount until they opened their bowels once or twice a day without straining. They were warned that bran might cause temporary flatulence and distension but that this would pass off in 3 weeks if they continued to take the bran. The patients were seen at the end of a month and again at the end of a second month to make sure that they had understood the instructions and that the bran was tolerated. It was emphasized that the bran was not a laxative to be taken at intervals for episodes of constipation but that it had to be taken daily for life.

Out of seventy patients only eight did not continue to take bran. The bowel habit, before and after taking bran, of the remaining sixty-two is shown in Fig. 3.

Most patients needed 2 teaspoonsful (12-14 g) of bran three times a day to render their stools easy to pass but some required several tablespoonsful a day. No fewer than thirty-nine of the sixty-two suffered from flatulence when they first took the bran but this disappeared within 3 weeks. Constipated patients passed soft stools daily after bran while those who had previously passed hard small stools frequently, 


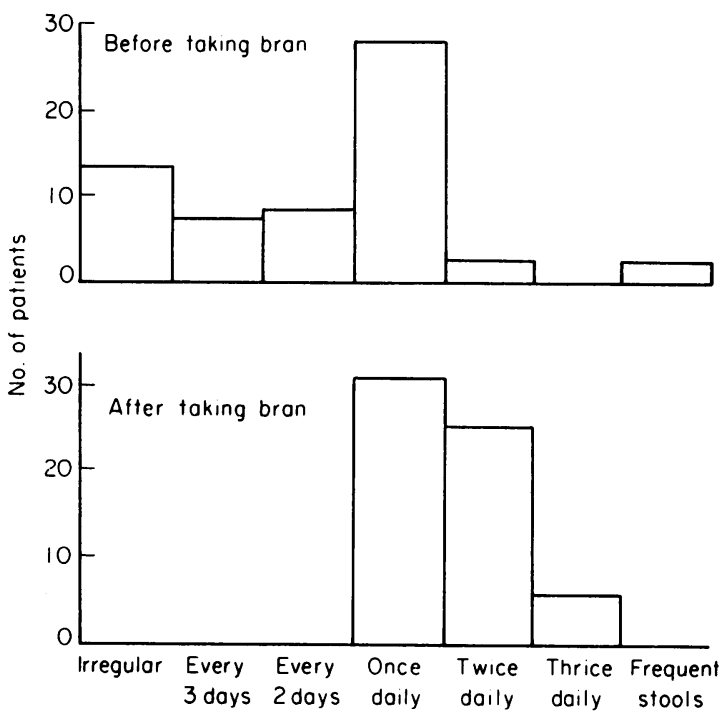

FIG. 3. Effect of unprocessed bran on the bowel habit in diverticular disease.

with episodes of diarrhoea, had fewer but bulkier motions. Before taking bran only eight of the sixtytwo had defaecated without straining but fifty-one were now enabled to pass their stools without effort. Some patients had felt that their rectum was never empty but, after bran, they evacuated their bowels completely.

\section{The relief of symptoms by the 'bran diet'}

All seventy patients complained of more than one presenting symptom; these are given in Table 2. Of the 171 symptoms, $14(8 \cdot 2 \%)$ were experienced by the eight patients who did not take bran regularly. Only
$6(3.8 \%)$ of the remaining 157 presenting symptoms were not relieved by the bran diet. Sixty-two (39.5\%) were relieved sufficiently to make the patients who had complained of them comfortable and $89(56.7 \%)$ were abolished by the bran diet.

Hence the addition of fibre in the form of bran, coupled with simple dietary changes, relieved or abolished $88.6 \%$ of the symptoms of uncomplicated diverticular disease.

No less than forty-nine of the seventy patients used laxatives before taking bran but of the sixty-two who then took bran, only seven required laxatives occasionally. The use of this natural and cheap remedy would save not only public funds but would also stop pensioners wasting money on laxatives whose prolonged use is not without risk. Patients who did not like bran were given Normacol Standard (Sterculia) which is the best alternative bulk former because it has not been known to clump and cause obstruction (Painter et al., 1972).

Hodgson (1972) gave methyl cellulose to six patients with diverticulosis. All had bulkier stools and became symptom free. The experience of this small series is similar to that described above but it would be a pity if expensive processed cellulose were to be used when bran is available and is so cheap.

\section{Bran and episodes of 'diverticulitis'}

One patient had been diagnosed previously as having recurrent left renal colic on three occasions. Intravenous pyelography showed a normal urinary tract, and a barium enema showed sigmoid diverticula. She did not subsequently experience severe pain during a 5-year period when she was taking bran and the slight discomfort which was occasionally noticed disappeared in 2 days on increasing the usual intake of bran. Twelve of the seventy patients

TABLE 2. Presenting symptoms of seventy patients with diverticular disease

\begin{tabular}{|c|c|c|c|c|c|}
\hline & \multirow{2}{*}{$\begin{array}{c}\text { Before } \\
\text { bran }\end{array}$} & \multirow{2}{*}{$\begin{array}{l}\text { Bran not } \\
\text { tolerated }\end{array}$} & \multicolumn{3}{|c|}{ Symptoms after bran } \\
\hline & & & Not relieved & Relieved & Abolished \\
\hline \multicolumn{6}{|l|}{ Dyspeptic symptoms } \\
\hline Nausea & 11 & 1 & 1 & 2 & 7 \\
\hline Heartburn & 2 & - & - & 2 & - \\
\hline Flatulence & 2 & - & 1 & 1 & - \\
\hline Distension & 36 & 4 & 2 & 14 & 16 \\
\hline Wind & 13 & - & - & 4 & 9 \\
\hline \multicolumn{6}{|l|}{ Painful diverticular disease } \\
\hline Right iliac fossa, pain or ache & 7 & - & - & 5 & 2 \\
\hline Left iliac fossa, pain or ache & 22 & 1 & 1 & 7 & 13 \\
\hline Lower or general abdominal pain & 28 & 3 & - & 11 & 14 \\
\hline Severe colic & 12 & 1 & - & 4 & 7 \\
\hline \multicolumn{6}{|l|}{ Bowel symptoms } \\
\hline Tender rectum & 4 & - & - & 1 & 3 \\
\hline Incomplete emptying of rectum & 6 & - & - & 3 & 3 \\
\hline Constipation & 28 & 4 & 1 & 8 & 15 \\
\hline Total & 171 & 14 & 6 & 62 & 89 \\
\hline
\end{tabular}


had recurrent severe Painful Diverticular Disease (Painter, 1968) and might well have required surgery to cure the condition. One was made comfortable with Normacol and the other eleven had their pain abolished by taking Allinsons' Bran Plus. Among them was the lady who had been treated for renal colic.

Thus a high fibre diet will relieve severe colic, and its widespread use would probably lessen the need for surgery in diverticular disease.

\section{The effect of bran on other diseases of the alimentary tract}

Other digestive diseases frequently co-exist with diverticulosis and it might be argued that 'roughage' and bran might adversely affect conditions such as duodenal ulcer. Bran improved the poor appetite of twenty-six of the sixty-two patients. No patient's appetite was made worse by bran.

No less than thirty-five of the seventy patients had barium meals, fourteen had cholecystograms and six had intravenous pyelograms during initial investigation and these showed that only eleven $(15.7 \%)$ had no other disease (Table 3). Nineteen patients had two other diseases and a 64-year-old obese woman had a hiatus hernia, a duodenal ulcer and diverticulosis and had already lost her appendix and gall-bladder. She has remained well on 2 tablespoonsful of bran daily for 33 months. In no case did bran aggravate the symptoms of any co-existent disease, probably because it becomes 'softage' when wet.

TABLE 3. Other diseases found in seventy patients with diverticula

\begin{tabular}{lr}
\hline Ischaemic heart disease & 13 \\
Hypertension & 13 \\
Appendicitis & 10 \\
Gall bladder and biliary disease & 9 \\
Duodenal ulcer & 8 \\
Hiatus hernia & 13 \\
Haemorrhoids & 6 \\
Rectal polyp & 3 \\
Varicose veins & 4 \\
Urinary tract infection and stone & 2 \\
Diabetes mellitus & \\
\hline
\end{tabular}

\section{Discussion}

Historical and epidemiological studies and animal experiments provide evidence that diverticular disease is a deficiency disease of Western civilization caused by the removal of cereal fibre from our modern diet. The replacement of this fibre in the form of wholemeal bread, together with miller's bran, will relieve or abolish the symptoms of uncomplicated diverticular disease in nearly every patient. Bran is safe and cheap and will also relieve constipation and the symptoms of early haemorrhoids.
The fibre depletion of our diet that occurred in the last century may be responsible not only for diverticulosis but also, at least in part, for some other 'modern' diseases which afflict the industrialized nations of the Western World. These include appendicitis, coronary artery disease, gallstones, diabetes mellitus and obesity (Burkitt, 1971; Burkitt et al., 1972; Cleave et al., 1969; Trowell, 1972a, b). All these diseases are still rare or unknown in countries where unrefined carbohydrates are eaten. Diverticulosis always occurs in communities where benign and malignant tumours of the colon are common. The two are related epidemiologically and are often found in the same patient. It has been shown that the bacteria in the colon of those who eat a low fibre diet degrade bile to form the precursors of carcinogens (Aries et al., 1969; Hill et al., 1971). A high fibre diet not only lessens the transit time, and hence the time available for this degradation to take place, but also reduces the time in which these carcinogens can be in contact with the colonic mucosa. Consequently the taking of fibre in the form of bran may help to prevent the development of cancer of the colon.

The symptoms of diverticular disease cannot be due to the diverticula as the bran diet relieves them while leaving the mucosal herniations in situ. If it is accepted that a low-fibre diet can so damage the colon that it literally 'ruptures' itself through struggling with small, stiff stools, it becomes obvious that it is extremely unlikely that the colon, and often only its sigmoid region, is the only part of the gut that is adversely affected by a fibre-deficient diet. The concept that an abnormal diet can alter the motility of the proximal alimentary tract as well as that of the colon would explain why bran alleviates the 'upper intestinal' symptoms that are so often associated with diverticulosis.

This concept might also throw some light on the origin of the symptoms of 'spastic colon', 'irritable colon' and 'irritable bowel syndrome'. These are illdefined conditions and are used as convenient terms to account for the presence of any unexplained 'belly-ache'. The 'irritable bowel syndrome' is said to be responsible for the symptoms of up to $60 \%$ of patients attending gastrointestinal clinics in whom no abnormality of the alimentary tract can be demonstrated. Experience shows that its symptoms often respond to a high fibre/low sugar diet.

The term 'irritable bowel syndrome' implies that these $60 \%$ of patients have abnormal alimentary tracts. On evolutionary grounds, it is extremely unlikely that such a high proportion of the population is born with a congenitally abnormal intestine. It has been suggested that it would be better to use the term Irritated Bowel Syndrome (Painter, 1972).

Such a change of emphasis in our thinking would be of the greatest importance. Normal intestinal 
tracts would no longer be blamed for symptoms that are almost certainly caused by our over-refined modern diet. We might then begin to retrace our dietary footsteps with the result that future generations would not develop diverticulosis or suffer from those other diseases of the colon that presently afflict our citizens.

\section{References}

Aries, V., Crowther, J.S., Drasar, B.S., Hill, M.J. \& Williams, R.E.O. (1969) Degradation of bile salts by human intestinal bacteria. Gut, 10, 575 .

Arfwidsson, S. (1964) Pathogenesis of multiple diverticula of the sigmoid colon in diverticular disease. Acta chirurgica scandinavica, Supplement, 342, 1.

Barker, T.C., MCKenzie, J.C. \& YudKin, J. (1966) Our Changing Fare. McGibbon and Kee: London.

Bland-Sutton, J. (1920) Section of surgery. Proceedings of the Royal Society of Medicine, 13, 5.

BurkitT, D.P. (1971) Epidemiology of cancer of the colon and rectum. Cancer, $28,3$.

Burkitt, D.P., Walker, A.R.P. \& Painter, N.S. (1972) Effect of dietary fibre on stools and transit-times, and its role in the causation of disease. Lancet, ii, 1408 .

Cleave, T.L. (1941) Natural bran in the treatment of constipation. British Medical Journal, 1, 461.

Cleave, T.L., Campbell, G.D. \& Painter, N.S. (1969) Diabetes, Coronary Thrombosis and the Saccharine Disease. John Wright: Bristol.

Cowgill, G.R. \& ANDERSon, W.E.J. (1932) Laxative effects of wheat bran and 'washed bran' in healthy men; comparative study. American Medical Association, 98, 1866.

Cruveilhier, J. (1849) Traité d'Anatomie Pathologique Générale, Paris, 1, 59.

Dimock, E.M. (1936) The Treatment of Habitual Constipation by the Bran Method. M.D. Thesis, University of Cambridge.

Drummond, H. (1917) Sacculi of intestine. British Journal of Surgery, 4, 407.

GRASER, E. (1899) Münchener medizinische Wochenschrift, 46, 721 .

Gross, S. (1845) Elements of Pathological Anatomy. Blanchard and Lea: Philadelphia.

Haberschon, S.O. (1857) Observations on the Alimentary Canal. Churchill: London.

Hill, M.J., Crowther, J.S., Drasar, B.S., Hawksworth, G., ARIES, V. \& Williams, R.E.O. (1971) Bacteria and etiology of cancer of large bowel. Lancet, i, 95 .

HoDgson, J. (1972) Effect of methylcellulose on rectal and colonic pressures in treatment of diverticular disease. British Medical Journal, 3, 729.

Hinton, J.M., Lennard-Jones, J.E. \& Young, A.C. (1969) A new method for studying gut transit times using radioopaque markers. Gut, 10, 842 .

KeELey, K.J. (1958) Alimentary disease in the Bantu. A review. Medical Proceedings, 4, 281.

KIM, E.H. (1964) Hiatus hernia and diverticulum of the colon. New England Journal of Medicine, 271, 764.

KLEBS, E. (1869) Handbuch der Pathologischen Anatomie. Hirschwald: Berlin.
Kocour, E.J. (1937) Diverticulosis of colon: its incidence in 7000 consecutive autopsies with reference to its complications. American Journal of Surgery, 37, 433.

Kyle, J., Adesola, A.O., Tinckler, L.F. \& de Beaux, J. (1967) Incidence of diverticulitis. Scandinavian Journal of Gastroenterology, 2, 75.

McCANCE, R.A. \& Widdowson, E.M. (1956) Breads, White and Brown. Pitman Medical: London.

PaINTER, N.S. (1962) Master of Surgery Thesis, University of London.

Painter, N.S. (1964) The etiology of diverticulosis of the colon with special reference to certain drugs. Annals of the Royal College of Surgeons of England, 34, 98.

PainTer, N.S. (1967) The correlation of the pressures in the human colon with the shape of the colonic lumen as shown by cineradiography. American Journal of Digestive Diseases, 13, 468.

PaInTER, N.S. (1968) Diverticular disease of the colon. British Medical Journal, 3, 475.

PaINTER, N.S. (1969) Diverticular disease of the colon-a disease of this century. Lancet, ii, 586.

PaINTER, N.S. (1970) Diverticulosis of colon-a disease of western civilization. British Medical Journal, 2, 450.

PaINTER, N.S. (1972) Irritable or irritated bowel. British Medical Journal, 2, 46.

Painter, N.S. \& BurkitT, D.P. (1971) Diverticular disease of the colon-a deficiency disease of western civilization. British Medical Journal, 2, 450.

Painter, N.S. \& Truelove, S.C. (1964) The intraluminal pressure patterns in diverticulosis of the colon. Gut, 5, 201.

Painter, N.S., Almeida, A.Z. \& Colebourne, K.W. (1972) Unprocessed bran in treatment of diverticular disease of the colon. British Medical Journal, 2, 137.

Painter, N.S., Truelove, S.C., Ardran, G.M. \& Tuckey, M. (1965) Segmentation and the localization of intraluminal pressures in the human colon with particular reference to the pathogenesis of colonic diverticula. Gastroenterology, 49, 169.

Rokitansky, C. (1849) A Manual of Pathological Anatomy, 2, 48. The Sydenham Society: London.

SlaCK, W.W. (1962) The anatomy, pathology and some clinical features of diverticulosis of the colon. British Journal of Surgery, 50, 185.

Stemmerman, G.N. (1970) Patterns of disease among Japanese living in Hawaii. Archives of environmental Health, 20, 266.

Telling, W.H.M. (1908) Acquired diverticula of the sigmoid flexure. Lancet, i, 843.

Telling, W.H.M. (1917) Acquired diverticula, diverticulosis and peridiverticulitis of the large intestine. British Journal of Surgery, 4, 468.

Telling, W.H.M. (1920) Diverticulitis. i, 85, and In: Proceedings of the Royal Society of Medicine, Section of Surgery, 13, 5.

Trowell, H.C. (1960) Non-infective disease in Africa. Arnold: London.

Trowell, H.C. (1972a) Dietary fibre and coronary heart disease. Revue Européenne d'Etudes Cliniques et Biologiques, 17,345 .

Trowell, H.C. (1972b) Crude fibre, dietary fibre and atherosclerosis. Atherosclerosis, 16, 138. 